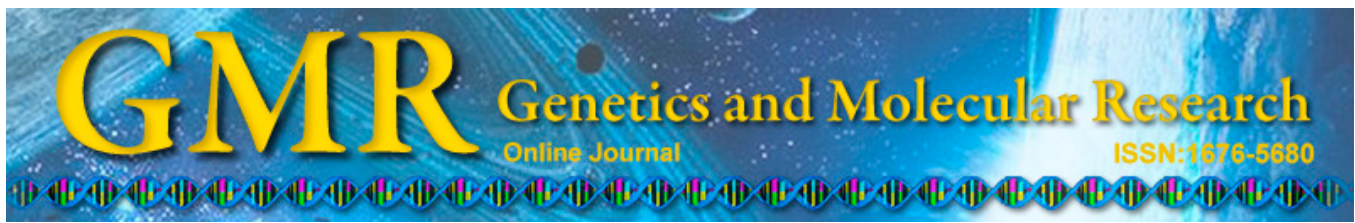

\title{
Cloprostenol and pregnant mare serum gonadotropin promote estrus synchronization, uterine development, and follicle-stimulating hormone receptor expression in mice
}

\author{
S. Wei ${ }^{1,3}$, Z. Gong ${ }^{2}$, L. An ${ }^{2}$, T. Zhang ${ }^{3}$, H. Dai ${ }^{3}$ and S. Chen ${ }^{3}$ \\ ${ }^{1}$ The Key Bio-Engineering and Technology Laboratory of National Nationality \\ Commission, Northwest University for Nationalities, Lanzhou, China \\ ${ }^{2}$ Medicine College, Northwest University for Nationalities, Lanzhou, China \\ ${ }^{3}$ Life Science and Engineering College, Northwest University for Nationalities, \\ Lanzhou, China
}

Corresponding author: S. Chen

E-mail: chensn_huining@163.com

Genet. Mol. Res. 14 (2): 7184-7195 (2015)

Received August 28, 2014

Accepted November 13, 2014

Published June 29, 2015

DOI http://dx.doi.org/10.4238/2015.June.29.12

\begin{abstract}
This study investigated the effects of pregnant mare serum gonadotropin (PMSG) and cloprostenol (CLO) on estrus induction and synchronization, uterine development, and follicle-stimulating hormone receptor (FSHR) expression in mice. A total of 105 Kunming pre-puberty mice were divided into seven subgroups. Three PMSG subgroups were injected intraperitoneally with 10, 20, and 40 IU PMSG twice (on days 0 and 4), and three CLO subgroups were injected intraperitoneally with 10,15 , and $20 \mu \mathrm{g}$ cloprostenol acetate twice (on days 0 and 4 ). The results showed that 93.33 and $66.67 \%$ of synchronized mice displayed estrus within 18.68-37.59 h following CLO and PMSG exposure, respectively. Estrus numbers, estrus onset time, and estrus rates in CLO and PMSG groups were greater than in control groups $(\mathrm{CG})(\mathrm{P}<0.05)$. Uterine weights of the PMSG group were higher than
\end{abstract}


that of CLO and CG groups, and the uterine horn longitudinal diameters in experimental mice were greater than CG. Expression levels of FSHR proteins in CLO and PMSG groups increased slightly when compared to CG. In conclusion, CLO and PMSG administration did not clearly affect the expression of uterine FSHR proteins in mice. Moreover, PMSG and CLO treatments synchronized estrus and enhanced the uterine development of mice. The efficacy of CLO on estrus synchronization was greater than PMSG, and the effects of PMSG on uterine development were stronger than CLO. These results have important significance regarding the modulation of animal reproductive functions.

Key words: Follicle-stimulating hormone receptor; Cloprostenol; Estrus synchronization; Uterine development; Mice;

Pregnant mare serum gonadotropin

\section{INTRODUCTION}

Estrus synchronization permits an increase of offspring each year, since it reduces the reproduction cycle and can occur regardless of the season. It also allows a uniform delivery time throughout the animal production unit. The use of hormonal products permits estrus synchronization for either natural mating or artificial insemination, which can improve the reproductive performance of animals. An alternative method for controlling reproduction is the use of prostaglandins, which eliminate the corpus lutein and induce a subsequent follicular phase with ovulation (Abecia et al., 2011, 2012). Administration of progesterone, progesterone analogues, and prostaglandins modify the luteal phase of the cycle (Abecia et al., 2012). Moreover, it also induces uterine contractions due to ecbolic properties, and it has an ovulatory effect, which is due to the immediate rise in gonadotropins (Friedman et al., 1991). Cloprostenol (CLO) is a potent prostaglandin (PGF) F2 $\alpha$ analogue that influences the estrus of animals by lysing appearance of the corpus lutein (Crawford et al., 2009). The intraperitoneal administration of CLO three days apart may induce the appearance of estrus in $80 \%$ of mice (Pallares and Gonzalez-Bulnes, 2009). However, there was no statistical difference in the pregnancy rates among cows that were injected with 150-500 $\mu \mathrm{g}$ CLO (Marcelo et al., 2010). Therefore, the actual effects of pregnant mare serum gonadotropin (PMSG) and CLO administration on animal estrus synchronization and uterine development remain unclear.

Although mice are laboratory animals widely used for research worldwide, research on the management of the estrus cycle in mice is scarce (Marcondes et al., 2002; Crawford et al., 2009; Alejandro et al., 2012). The usual methods for the induction of behavioral estrus and ovulation are the "male effect" by the introduction of a fertile or vasectomized male and the "Whitten effect," which utilizes exposure to male pheromones. However, the degree of estrus synchronization was found to be limited. Thus, the application of a reliable method for estrus synchronization would be of interest for the improvement of animal management, research, and well-being (i.e., reducing the amount of experimental animals and refining studies) (Pallares and Gonzalez-Bulnes, 2009).

The intraperitoneal administration of CLO three days apart may se of prostaglandins, which eliminate the corpus lutein and induce the appearance of estrus in $80 \%$ of mice within 72-96 h (Pallares and Gonzalez-Bulnes, 2009), but the degree of estrus synchronization 
was not reported. Furthermore, no information is available regarding comparative research on the fertility and uterine development after PMSG and CLO treatment in mice (Pallares and Gonzalez-Bulnes, 2009). It is unknown whether PMSG and CLO treatments impact folliclestimulating hormone receptor (FSHR) localization and FSHR protein expression in the uteri of mice (Schirman-Hildesheim et al., 2005; Crawford et al., 2009).

Based on the results of our previous research (Wei et al., 2013), the present study aimed to explore the effects of CLO and PMSG at different doses on estrus induction and synchronization, uterine development, and FSHR protein expression in mice. Moreover, we also investigated the correlation between the expression levels of FSHR proteins and uterine development indexes of mice in order to determine the mechanisms of PMSG and CLO involved in modulating uterine development and estrus synchronization, which may improve animal fertility.

\section{MATERIAL AND METHODS}

\section{Animals}

The experiments were performed on a total of 105 pre-puberty Kunming (KM) female mice (Mus musculus) that were 30 days old with body weights of $25.28 \pm 2.26 \mathrm{~g}$. Animals were purchased from the Experiment Animal Center of Lanzhou University of China [License No. SCXK (Gansu) 2005-0007]. All mice were pure KM strain and healthy based on clinical examinations. Mice were raised in subgroups and kept in mouse cages equipped with automatic water dispensers. Room conditions were maintained at $22-24^{\circ} \mathrm{C}$ and $30-60 \%$ relative humidity with a controlled 12-h light-dark cycle. Mice received a commercial diet (Lanzhou Taihua Feed Co. Ltd, China) depending on their physiological condition, and water was supplied ad libitum.

The experiment commenced after a seven-day adjustment period. All mice were randomly divided into PMSG-1, PMSG-2, PMSG-3, CLO-1, CLO-2, CLO-3, and control group (CG) subgroups $(\mathrm{N}=15)$. The body weight of each mouse was weighed on an electronic scale once per day. All animal procedures were conducted in strict accordance with the Experiment Animal Care and Use Committee of Gansu Province, the China.

\section{Experimental designs}

For the PMSG group, mice in PMSG-1, PMSG-2, and PMSG-3 subgroups were intraperitoneally injected with 10, 20, and 40 IU PMSG (Ningbo Sansheng Pharmaceutical Co. Ltd., Ningbo, Zhejiang, China), respectively, twice (on days 0 and 4 ) in the morning (8-9:00 a.m.). Mice in CLO-1, CLO-2, and CLO-3 subgroups were intraperitoneally injected with 10 , 15, and $20 \mu \mathrm{g}$ cloprostenol acetate (Ningbo Sansheng Pharmaceutical Co. Ltd.), respectively, twice (on days 0 and 4) in the morning (8-9:00 a.m.). Before PMSG and CLO injection, the hormones were diluted 10 -fold with normal saline to decrease pain. CG mice were intraperitoneally injected with $0.5 \mathrm{~mL}$ normal saline twice (on days 0 and 4 ) in the morning (8-9 AM).

\section{Estrus detection}

Estrus was detected by clinical observation and mouse vaginal smears twice daily 
after the initial appearance of behavioral estrus based on previous descriptions (Batra and Sidhar, 1969; Marcondes et al., 2002; He et al., 2007).

Fresh vaginal smears were examined twice daily for $72 \mathrm{~h}$ after the second hormone injection. The estrus onset time (EOT) in each mouse was determined after the second hormone injection continuously for $72 \mathrm{~h}$ based on vaginal smears. The values of EOT and estrus rates were recorded. The average of each subgroup was calculated based on the data of five mice in the subgroup.

\section{Sample collections}

Five mice from each subgroup were anesthetized by injecting $0.1 \mathrm{mg} / \mathrm{kg}$ xylazine intraperitoneally, and they were subsequently killed by cervical dislocation on days 7, 14, and 21 following the first injection of CLO and PMSG. The left and right uteri of each mouse were dissected aseptically, and were immediately weighed on an electronic scale. The uterine horn longitudinal diameter (ULD) and uterine horn transverse diameter (UTD) of the left and right uteri of each mouse were measured with a vernier caliper. The average value was calculated based on the left and right uterine horn of each mouse. Collected uterine samples were then fixed in $10 \%$ formaldehyde. Additionally, the blood samples of five mice from each subgroup were aseptically collected using vacutainers (Zhejiang Gongdong Medical Technology Co. Ltd., Zhejiang, China) on days 7, 14, and 21 after mice were anesthetized using the methods described above.

The samples were allowed to clot for $2 \mathrm{~h}$ at room temperature. After centrifugation $(3000 \mathrm{~g}, 20 \mathrm{~min})$, the serum was stored at $-20^{\circ} \mathrm{C}$ until analysis.

\section{Histological image measurement of uteri}

Tissue samples fixed in 10\% formaldehyde were embedded in paraffin wax, sliced ( 5 $\mu \mathrm{m})$, and stained with hematoxylin and eosin (H\&E). The sections were photographed under a light microscope (Leica, Japan). Five sites in each section (four sections in every subgroup, totaling 140 sites for each subgroup) were measured. The uterine wall thickness (UWT), uterine endometrial thickness (UET), uterine perimetrium thickness (UPT), and longitudinal diameters of endometrial epithelial cells (LEEC) were measured using the Images Advanced 3.2 and the Image Pro Plus 2.0 software (MOTIC Company, Hong Kong, China).

\section{Western blotting analysis}

To evaluate FSHR protein expression in the uteri of mice after hormone administration, western blotting was performed according to methods described (Wei et al., 2012, 2013). The relative content of FSHR proteins was presented as the ratio between gray values of FSHR separated by that of $\beta$-actin. The experiments were replicated three times, and the negative control was performed without a primary antibody.

\section{Statistical analyses}

Statistical analyses were conducted using SPSS v. 18.0 (SPSS Inc., Chicago, IL, USA). For each subgroup, the averages of all parameters described above (including body weight and daily gains, uterine weight, EOT, estrus rates, ULD, and UTD) were calculated based on the 
data from five mice in each subgroup. Data are reported as means \pm SE. After a square root transformation of the data, all variables complied with the assumptions for a one-way ANOVA. When significant differences were identified, supplementary Tukey's post-hoc tests were conducted to investigate pairwise differences. $\mathrm{P}<0.05$ was considered to be statistically significant. Pearson's model was utilized to analyze correlations between uterine parameters, serum hormone levels, and FSHR expression. When significant differences were identified, supplementary Tukey's post-hoc tests were conducted to investigate pairwise differences. $\mathrm{P}<0.05$ was considered to be statistically significant.

\section{RESULTS}

\section{Estrus synchronization}

Reproductive data on mice synchronized with PMSG and CLO are summarized in Table 1. As shown in Table 1, estrus numbers and the estrus rate of CLO and PMSG groups were higher than that of $\mathrm{CG}(\mathrm{P}<0.05$ or $\mathrm{P}<0.01)$. The EOT of CLO and PMSG groups were shorter than $C G(P<0.05$ or $\mathrm{P}<0.01)$, and the estrus rate of the CLO group was larger than that in the PMSG group. The average EOT in CLO and PMSG groups was $19.88 \pm 2.91$ hours and $34.84 \pm$ 5.05 hours, respectively, and the EOT of the CLO group was less than that of the PMSG group. Furthermore, the EOT in CLO-3 and PMSG-3 was less than that in the CLO-1 and CLO-2 and PMSG-1 and PMSG-2 subgroups $(\mathrm{P}<0.05)$, respectively. However, the estrus rates of CLO-3 and PMSG-3 were greater than those in the CLO-1 and CLO-2 and PMSG-1 and PMSG-2 subgroups $(\mathrm{P}<0.05)$, respectively. The results indicate that $60.00 \%-93.33 \%$ of the synchronized mice displayed estrus within 18.68-37.59 $\mathrm{h}$ after the CLO and PMSG administration.

\begin{tabular}{|c|c|c|c|c|c|}
\hline Group & Subgroup & Mice No. & Estrus No. & EOT (h) & Estrus rate (\%) \\
\hline \multirow[t]{3}{*}{$\overline{\mathrm{CLO}}$} & CLO-1 & 15 & 14 & $21.04 \pm 2.75^{* *}$ & $93.33 * *$ \\
\hline & CLO-2 & 15 & 15 & $19.52 \pm 2.81 * *$ & $100.00^{* *}$ \\
\hline & CLO-3 & 15 & 13 & $18.68 \pm 3.16^{* *}$ & $86.67^{*}$ \\
\hline \multirow[t]{3}{*}{ PMSG } & PMSG-1 & 15 & 9 & $37.59 \pm 5.62$ & 60.00 \\
\hline & PMSG-2 & 15 & 11 & $34.51 \pm 4.73 *$ & 73.33 \\
\hline & PMSG-3 & 15 & 10 & $32.42 \pm 4.81^{*}$ & 66.67 \\
\hline Control & $\mathrm{CG}$ & 15 & 7 & $53.43 \pm 6.62$ & 46.67 \\
\hline
\end{tabular}

EOT- Estrus onset time (h). $* \mathrm{P}<0.05$ when compared to $\mathrm{CG} ; * * \mathrm{P}<0.01$ when compared to $\mathrm{CG}$.

\section{Uterine weights, UTD, and UPD of mice}

During the experiment, the uterine weights of six subgroups were larger than that of the control subgroup (Table 2). The uterine weight of the PMSG group was higher than that of the CLO group, with a maximum measured in the PMSG-3 subgroup. On days 7, 14 and 21, the uterine weight of the PMSG-3 subgroup was greater when compared to the $\mathrm{CG}$ ( $\mathrm{P}<0.05$ or $\mathrm{P}<0.01)$. Additionally, on day 7, the uterine weights of PMSG-1 and PMSG-2 were also greater than the CG $(\mathrm{P}<0.05)$. These results illustrate that PMSG and CLO treatment may promote uterine development, and that the efficacy of PMSG is greater. 
Table 2. Measurements of uterine parameters and uterine weight percentage in mice.

\begin{tabular}{|c|c|c|c|c|c|c|c|c|c|c|c|c|}
\hline \multirow[t]{2}{*}{ Subgroup } & \multicolumn{3}{|c|}{ Uterine weights (g) } & \multicolumn{3}{|c|}{$\mathrm{ULD}(\mathrm{cm})$} & \multicolumn{3}{|c|}{ UTD (cm) } & \multicolumn{3}{|c|}{ Percentage (\%) } \\
\hline & $7 \mathrm{~d}$ & $14 \mathrm{~d}$ & $21 \mathrm{~d}$ & $7 \mathrm{~d}$ & $14 d$ & 21d & $7 \mathrm{~d}$ & $14 d$ & 21d & $7 d$ & $14 d$ & $21 \mathrm{~d}$ \\
\hline CG & 0.058 & 0.069 & 0.071 & 0.64 & 0.67 & 0.70 & 0.10 & 0.11 & 0.11 & 22.56 & 23.78 & 23.12 \\
\hline CLO-1 & 0.093 & 0.090 & 0.076 & 0.78 & 0.86 & 0.97 & 0.11 & $0.22 *$ & 0.13 & 25.35 & $28.22 *$ & 24.16 \\
\hline CLO-2 & 0.056 & 0.082 & 0.082 & 0.66 & 0.70 & 0.73 & 0.18 & 0.18 & $0.20 *$ & 24.35 & $28.28 * *$ & 24.30 \\
\hline CLO-3 & 0.064 & 0.072 & 0.109 & 0.53 & 0.63 & 0.66 & 0.14 & 0.16 & 0.16 & 24.80 & $27.40 *$ & 25.47 \\
\hline PMSG-1 & $0.141^{*}$ & 0.122 & 0.107 & 0.92 & 1.03 & 1.12 & 0.13 & 0.19 & $0.21 *$ & 26.50 & $29.02 * *$ & $27.26^{*}$ \\
\hline PMSG-2 & $0.137^{*}$ & 0.107 & 0.128 & 1.06 & $1.22 *$ & $1.34^{*}$ & 0.18 & $0.21 *$ & $0.25 * *$ & $30.10^{* *}$ & $30.57 * *$ & $27.14 *$ \\
\hline PMSG-3 & $0.169 *$ & $0.142 *$ & $0.155^{*}$ & 1.16 & $1.25^{*}$ & $1.36^{*}$ & 0.16 & 0.18 & $0.20^{*}$ & $29.74 * *$ & $28.84 *$ & $28.02 *$ \\
\hline
\end{tabular}

ULD $=$ uterine horn longitudial diameters; UTD = uterine horn transverse diameters. Percentage: The uterus weight of each mouse was divided by its body weight. $* \mathrm{P}<0.05$ when compared to $\mathrm{CG}$; $* * \mathrm{P}<0.01$ when compared to $\mathrm{CG}$.

As shown in Table 2, ULD and UTD values in the experimental subgroups (excluding CLO-2) were larger than that of the CG. However, ULD values in the PMSG group were greater than that of the CLO and CG groups $(\mathrm{P}<0.05$ or $\mathrm{P}<0.01)$. Moreover, ULDs in PMSG2 and PMSG-3 were significantly higher when compared to the $\mathrm{CG}(\mathrm{P}<0.05$ or $\mathrm{P}<0.01)$. In comparison with the CG, the UTD values of mice treated with PMSG and CLO also increased (Table 2). On days 14 and 21, the UTD values of the CLO-1, PMSG-1, PMSG-2, and PMSG-3 subgroups were significantly larger than that of $\mathrm{CG}(\mathrm{P}<0.05$ or $\mathrm{P}<0.01)$. The findings indicate that PMSG and CLO treatment may improve the growth of mice.

Additionally, the uterine weight percentages (\%) that accounted for body weights in PMSG and CLO groups of mice were greater than that in the CG group (Table 2). On day 14, the percentage of the PMSG group was significantly higher than the $\mathrm{CG}(\mathrm{P}<0.05$ or $\mathrm{P}<0.01)$, especially in the PMSG-2 subgroup $(\mathrm{P}<0.01)$. This result demonstrates that PMSG and CLO treatment may promote uterine growth in mice.

\section{Measurements of UWT, UET, UPT, and LEEC in mice}

The changes in UWT, UET, UPT, and LEEC are shown in Figures 1-3. The UWT of the PMSG group was higher than that of CLO and CG groups. Compared to the control group, the UWT of the PMSG-2 and PMSG-3 subgroups significantly increased $(\mathrm{P}<0.05)$.

The UET of the PMSG group was higher than that of the CLO and CG groups, and the UET of the CLO-3 and PMSG-3 subgroups was significantly thickened $(\mathrm{P}<0.05)$ compared to the CG and other subgroups. The UPT of mice increased along with the doses of PMSG and CLO administration. On day 21, the UPT of the CLO-3 subgroup and the PMSG group were significantly larger than that of the $\mathrm{CG}$ group $(\mathrm{P}<0.05)$. However, there were no significant differences in LEEC values between experimental groups and the control group. The findings demonstrate that PMSG and CLO may promote the development and growth of mouse uteri, especially UPT, since the effects were dose-dependent.

\section{Western blotting of FSHR protein in uteri}

Uterine FSHR protein was detected by western blotting in all mouse samples. Moreover, changes in FSHR protein expression levels differed among all groups (Figure 4). Compared to the CG, expression levels of FSHR proteins in CLO and PMSG groups increased slightly along with the CLO and PMSG injection doses. However, there were no significant 
differences between the experimental groups and the control group. This results suggests that CLO and PMSG administration did not obviously affect the expression of FSHR proteins in the uteri of mice.

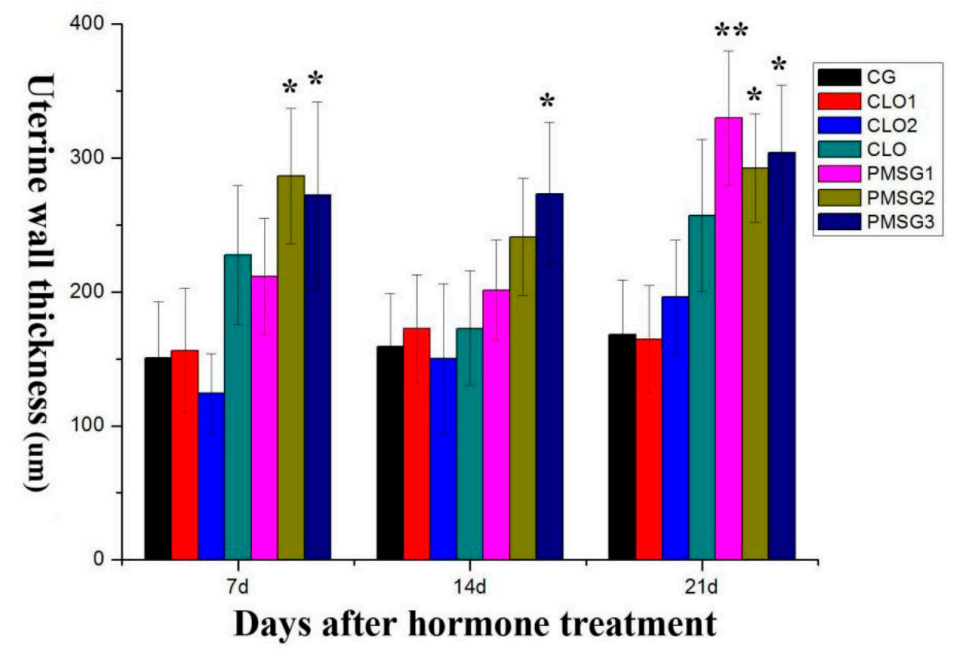

Figure 1. Uterine wall thickness (UWT) of mice after PMSG and CLO treatment. UWT of the PMSG group was higher than that of the CLO and CG groups. UWT of the PMSG-2 and PMSG-3 subgroups were significantly increased when compared to the CG. *The difference was significant $(\mathrm{P}<0.05)$ when compared to the CG. ${ }^{*}$ The difference was highly significant $(\mathrm{P}<0.01)$ when compared to the $\mathrm{CG}$.

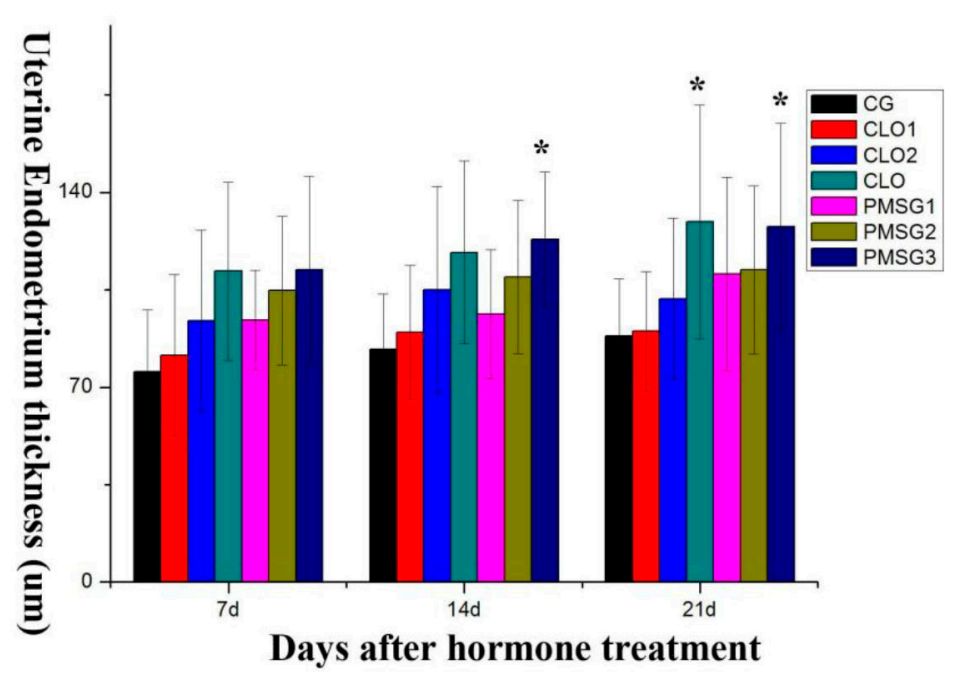

Figure 2. Uterine endometrial thickness (UET) of mice after PMSG and CLO treatment. UET of the PMSG group was higher than that of the CLO and CG groups. UET of the CLO-3 and PMSG-3 subgroups was significantly thickened when compared to the CG and other subgroups. *The difference was significant $(\mathrm{P}<0.05)$ when compared to the CG. 


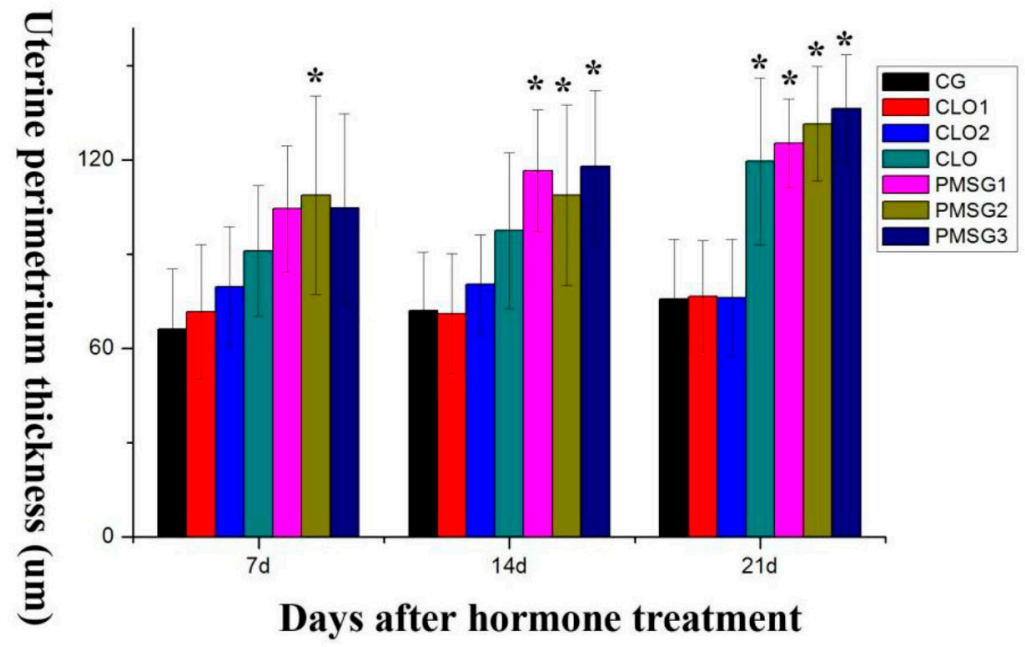

Figure 3. Uterine perimetrium thickness (UPT). The UPT of mice increased along with the doses of PMSG and CLO administered. On day 21, UPT of the CLO-3 subgroup and PMSG group was significantly larger than that of the $\mathrm{CG}$ group $(\mathrm{P}<0.05)$. *Difference was significant $(\mathrm{P}<0.05)$ when compared to CG.

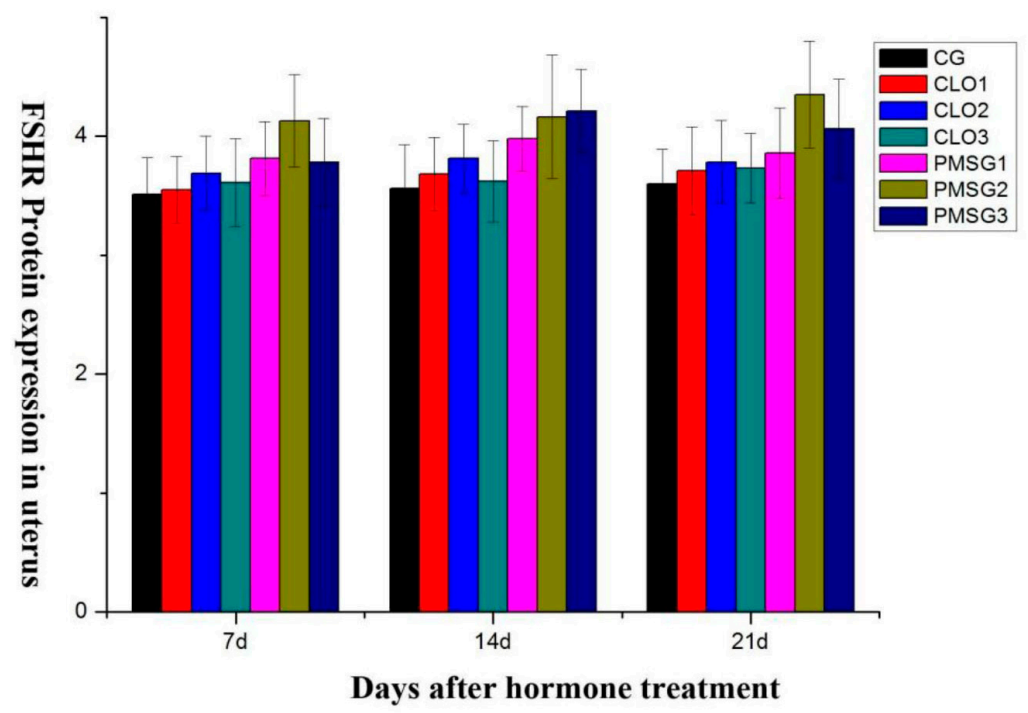

Figure 4. FSHR protein expression in the uteri of mice. Expression levels of FSHR proteins in CLO and PMSG groups increased along with the CLO and PMSG injection doses as compared to the CG.

\section{Correlations between protein expression and uterine development}

As shown in Table 3, Pearson's correlation analyses in the PMSG group demonstrated that UW had a significant positive correlation with ULD, UET, and UPT $(\mathrm{r}=0.7331, \mathrm{r}=$ 0.7426 , and $\mathrm{r}=0.6720$, respectively; $\mathrm{P}<0.05$ or $\mathrm{P}<0.01$ ). FSHR expression levels also had 
significant positive correlations with ULD, UTD, UPT, UWT, and UET $(\mathrm{P}<0.05$ or $\mathrm{P}<0.01)$. Moreover, there were also highly significant positive correlations between UWT, UET, and UPT $(\mathrm{P}<0.01)$. Therefore, the increase in CLO and PMSG injection dose may promote uterine development and FSHR expression.

For the CLO group (data not shown), Pearson correlation analyses indicated UW had a significant positive correlation with UWT $(\mathrm{r}=0.6598, \mathrm{P}<0.05)$. Additionally, UWT had a significant positive correlation with UET $(\mathrm{r}=0.5848, \mathrm{P}<0.05)$ and UPT $(\mathrm{r}=0.6504, \mathrm{P}<0.05)$.

Table 3. Pearson correlation analyses of parameters in mice treated with PMSG.

\begin{tabular}{|c|c|c|c|c|c|c|c|c|}
\hline Items & BW & UW & ULD & UTD & UWT & UET & UPT & LEEC \\
\hline UW & 0.3856 & & & & & & & \\
\hline ULD & 0.5351 & $0.7331 * *$ & & & & & & \\
\hline UTD & 0.4636 & 0.4525 & $0.8900^{*}$ & & & & & \\
\hline UWT & 0.5624 & 0.6704 & $0.8671^{*}$ & $0.8101^{* *}$ & & & & \\
\hline UET & $0.6778 *$ & $0.7426^{* *}$ & $0.9465^{* *}$ & $0.7565^{* *}$ & $0.8808^{* *}$ & & & \\
\hline UPT & 0.5675 & $0.6720^{*}$ & $0.9364 * *$ & $0.8895^{* *}$ & $0.8752 * *$ & $0.8697 * *$ & & \\
\hline LEEC & 0.3576 & 0.4179 & 0.2737 & 0.2574 & 0.3365 & 0.2441 & 0.2985 & \\
\hline FSHR & 0.3003 & 0.5183 & $0.8810^{*}$ & $0.8751^{* *}$ & $0.7079 * *$ & $0.7722 *$ & $0.8293 * *$ & 0.1395 \\
\hline
\end{tabular}

$\mathrm{BW}=$ body weight $\mathrm{UW}=$ uterus weight $\mathrm{ULD}=$ uterine horn longitudinal diameters; $\mathrm{UTD}=$ uterine horn transverse diameters; UWT $=$ uterine wall thickness; UET $=$ uterine endometrium thickness; UPT $=$ uterine perimetrium thickness; FSHR $=$ FSH receptor; LEEC $=$ longitudinal diameters of endometrium epithelial cells. $* \mathrm{P}<0.05$ when compared to $\mathrm{CG} ; * * \mathrm{P}<0.01$ when compared to $\mathrm{CG}$.

\section{DISCUSSION}

In this study, $105 \mathrm{KM}$ female mice were utilized. At the beginning of the experiment, the mice had reached puberty, and they became mature in the mid-stage of the experiment (at about 45 days old). These conditions allowed enhanced estrus synchronization.

The estrus behaviors were classified into four stages: proestrus, estrus, metestrus, and diestrus, which were similar to stages utilized in previous studies (Batra and Sidhar, 1969; Marcondes et al., 2002). The estrus synchronization rates for the CLO and PMSG treatments ( $93.33 \%$ and $66.67 \%$, respectively) were obtained in the present study, and they are similar to early reports in mice (Pallares and Gonzalez-Bulnes, 2009), ewes (He et al., 2007; Alejandro et al., 2012), and heifers (Richardson et al., 2002). However, the estrus synchronization rates were greater than those detected in earlier studies (Pallares and Gonzalez-Bulnes, 2009). The intraperitoneal administration of CLO three days apart may induce estrus in $80 \%$ of mice within 72-96 h (Pallares and Gonzalez-Bulnes, 2009). Moreover, Alejandro et al. (2012) reported that $90 \%$ and $70 \%$ of ewes showed estrus synchronization following CLO and fluorogestone acetate exposure, respectively, in combination with PMSG in sheep (Alejandro et al., 2012). In another report, the estrus rates were $40 \pm 16.3 \%$ and pregnancy/lambing rates were slightly higher in ewes (Chen, 2011).

In our study, the estrus rates in CLO and PMSG groups were greater than that in the $\mathrm{CG}$, with a maximum estrus rate detected in CLO-2. This result indicates that the dose of CLO and PMSG might influence the efficacy of estrus synchronization in mice. The effects of CLO were stronger than that of PMSG, and intraperitoneal administration of $15 \mu \mathrm{g}$ CLO twice (on days 0 and 4) had optimum efficacy of estrus synchronization in mice. This is likely due to the promotion of LH secretion and an increase of serum LH and FSH concentrations after the CLO and PMSG injections. Our study also demonstrated that PMSG and CLO treatments in 
mice may promote the secretion of $\mathrm{LH}$ and FSH.

It is important to note that progestogens are ineffective in anestrus animals (He et al., 2007). Furthermore, the efficiency is increased when used in combination with other hormones such as PMSG. A previous study indicated that $25.0 \%, 20.8 \%$, and $50.0 \%$ of treated ewes showed signs of estrus $24 \mathrm{~h}, 48 \mathrm{~h}$, and $72 \mathrm{~h}$ after applying the CLO treatment, respectively (He et al., 2007). Moreover, the EOT shortened slightly in the hormone-treated ewes (Knights et al., 2000). In our study, the synchronized mice displayed estrus within 18.68-37.59 $\mathrm{h}$ after the CLO and PMSG injections, and the EOT of the CLO and PMSG groups was shorter than that of the CG. In addition, a shorter EOT was observed in the CLO group when compared to the PMSG group. Based on this, our results are consistent with early reports (Knights et al., 2000; Richardson et al., 2002), but the findings are lower than those of previous reports. For instance, ewes displayed estrus within $72-96 \mathrm{~h}$ following intraperitoneal administration of CLO (Richardson et al., 2002). Relative to large animals (such as cows and ewes), the high doses of PMSG administered in this study were based on our experiences and early studies (Wei et al., 2012). The results showed that such high doses could be used to synchronize estrus in mice, and that the exact mechanisms still need to be further explored.

Previous studies indicated that GnRH agonist treatment could significantly reduce uterine growth (Weeks, 1999; Sun et al., 2007; Wei et al., 2011). For example, the uterine volume was reduced by $36 \%$ at 12 weeks and $45 \%$ at 24 weeks after subcutaneous injection of $3.75 \mathrm{mg}$ of GnRH (Friedman et al., 1991). Moreover, the uterine weights in mice treated with GnRH agonist immunization decreased by $34.43 \%-55.74 \%$ when compared with controls, and uterine wall thickness was reduced by $8.64 \%-14.03 \%$ (Wei et al., 2011). Our results indicate that the uterine weights of the treated mice increased as compared to the CG. Furthermore, the uterine weights of the PMSG group were higher than that of CLO group, with a maximum observed in the PMSG-3 subgroup. ULD values in experimental subgroups (excluding CLO2) were larger than that of the CG during the experiment, and ULD values in the PMSG group were greater than that in CLO group. In comparison with CG, UTD values of mice treated with PMSG and CLO also increased. Thus, the findings demonstrated that PMSG and CLO treatments may promote uterine development and growth, especially regarding UPT. The results suggest that PMSG had a greater efficacy, and that the effects were dose-dependent. Our results differ from previous reports (Chia et al., 2006; Wei et al., 2012), but the mechanisms associated with the effects need to be further explored in the future.

Western blotting analysis indicated that PMSG and CLO did not remarkably impact FSHR protein expression levels. Agca et al. (2013) reported that the exogenous hormones used for estrus synchronization and ovarian hyper stimulation had minimal effects on gene expression, whereas induction of ovulation caused major changes in the gene expression of rats. However, there are few documents about the effects of exogenous hormones on FSHR protein expression (Marek et al., 2014). Therefore, the findings in our experiment need to be further investigated.

There is little information about the changes in body weight and daily gains after estrus synchronization treatment (Alejandro et al., 2012; Agca et al., 2013). In this study, the body weight of PMSG-3 subgroups was higher than that of the remaining subgroups. However, on day 21, the body weight of the CLO-1 subgroup was lower than that of the CG. Furthermore, daily gains in the PMSG-3 subgroup were higher than that in the CG and CLO-2 subgroups on days 3 and 5. These results demonstrated that the injection of 40 IU PMSG may enhance the growth of mice in a more remarkable manner than other PMSG doses and CLO 
treatments. To date, there have been no reports of correlations between uterine development indexes and hormone treatment in mice (Hirsbrunner et al., 2003; Fhulufhelo et al., 2012). Therefore, our results need to be verified in a future study.

The Pearson's correlation analyses in the present study demonstrated that significant positive correlations existed between uterine weight and UWT, ULD, UET, and UPT. Additionally, UWT had significant positive correlations with UET and UPT, and there were significant positive correlations between FSHR protein expression levels and uterine parameters (such as ULD, UTD, UPT, UWT, and UET). Specifically, the increase in uterine development is due to the increment of UWT, UET, and UPT. To date, no similar reports have been published. Thus, the actual statistical correlations between these parameters need further research. Our results present a novel thought and method for quantitatively studying the effects of PMSG and CLO on the reproductive functions in animals and humans.

\section{CONCLUSION}

PMSG and CLO treatments in mice may synchronize estrus and enhance uterine development and growth. The results indicate that the efficacy of CLO on estrus synchronization was greater than PMSG. However, the effects of PMSG on uterine development were stronger than CLO. These results have important significance regarding the modulation of reproductive functions and the treatment of uterine diseases in women and animals.

\section{Conflicts of interest}

The authors declare no conflict of interest.

\section{ACKNOWLEDGMENTS}

Research supported by the Innovation Team Project for Animal Medical and Biological Engineering of Ministry of Education of China, the Agricultural Biotechnology Research and Application Development Projects of Gansu Province of China, and the National Science and Technology Support Program Projects of 11th five-year plan of China.

\section{REFERENCES}

Abecia JA, Forcada F and González-Bulnes A (2011). Pharmaceutical control of reproduction in sheep and goats. Vet. Clin. Food. Anim. 27: 67-79.

Abecia JA, Forcada F and González-Bulnes A (2012). Hormonal control of reproduction in small ruminants. Anim. Reprod. Sci. 130: 173-179.

Agca C, Yakan A and Agca Y (2013). Estrus synchronization and ovarian hyper-stimulation treatments have negligible effects on cumulus oocyte complex gene expression whereas induction of ovulation causes major expression changes. Mol. Reprod. Dev. 80: 102-117.

Alejandro CI, Manuel XCV and Gustavo RLC (2012). Effect of cloprostenol and fluorogestone acetate more PMSG on synchronization and no return to estrus in seasonal anestrus Dorper sheep. J. Appl. Sci. Res. 8: 1612-1614.

Batra BK and Sidhar AP (1969). Vaginal smear in mice as an indicator of ova in oviduct. Indian J. Exp. Biol. 7: 93-95.

Chen XY (2011). Experiment of promoting synchronous estrus in sheep with prostaglandin and vaginal sponge plug. Chin. Qinghai J. Anim. Vet. Sci. 41: 23-24.

Chia CC, Huang SC and Chen SS (2006). Ultrasonographic evaluation of the change in uterine fibroids induced by treatment with a GnRH analog. Taiwan J. Obstet. Gynecol. 5: 124-128. 
Crawford JL, Heath DA, Haydon LJ, Thomson BP, et al. (2009). Gene expression and secretion of LH and FSH in relation to gene expression of GnRH receptors in the brushtail possum (Trichosurus vulpecula) demonstrates highly conserved mechanisms. Reproduction 137: 129-140.

Fhulufhelo VR, Tshimangadzo LN, Ben S, Johannes PCG, et al. (2012). Oestrous synthronisation and pregnancy rate following artificial insemination (AI) in South African indigenous goats. J. Appl. Anim. Res. 40: 292-296.

Friedman AJ, Hoffman DI and Comite F (1991). Treatment of leiomyomata uteri with leuprolide acetate depot a double blind, placebo controlled, multicenter study. Obstet. Gynecol. 77: 720-725.

He QM, Xiao SJ and Xia HM (2007). An observational study on vaginal smear of rats. Acad. J. Guangzhou Med. Coll. 35: 4-7.

Hirsbrunner G, Knutti B, Küpfer U, Burkhardt H, et al. (2003). Effect of prostaglandin E2, dl-cloprostenol, and prostaglandin E2 in combination with d-cloprostenol on uterine motility during diestrus in experimental cows. Anim. Reprod. Sci. 9: 17-32.

Knights M, Hoenh T, Lewis PE and Inskeep EK (2000). Effectiveness of intravaginal progesterone inserts and FSH for inducing synchronized estrus and increasing lambing rate in anestrous ewes. J. Anim. Sci. 79: 1120-1131.

Marcelo GMC, Paulo TFA, Orivaldo SJ, Leandro I, et al. (2010). Effects of lower doses of cloprostenol intramuscular or into vulvar submucosa on estrus induction and pregnancy rates in Nelore cows. Semina: Ciências Agrárias, Londrina31: 451-458.

Marcondes FK, Bianchi FJ and Tanno AP (2002). Determination of the estrous cycle phases of rats: some helpful considerations. Braz. J. Biol. 62: 609-614.

Marek B, Marta W, Anna K, Iwona B, et al. (2014). The effect of hormonal estrus induction on maternal effect and apoptosis-related genes expression in porcine cumulus-oocyte complexes. Reprod. Biol. Endocrinol. 12: 32.

Pallares P and Gonzalez-Bulnes A (2009). A new method for induction and synchronization of oestrus and fertile ovulations in mice by using exogenous hormones. Lab. Anim. 43: 295-299.

Richardson AM, Hensley BA, Marple TJ and Jonson SSK (2002). Characteristic of estrus before and first insemination and fertility of heifers after synchronized estrus using GnRH, PGF2a, and progesterone. J. Anim. Sci. 80: 2792-2800.

Schirman-Hildesheim TD, Bar T and Aroya NB (2005). Differential GnRH and GnRH-receptor mRNA expression patterns in different tissues of the female rat across the estrous cycle. Endocrinology 146: 3401-3408.

Sun P, Yu X, Yang Y, et al. (2007). Efficacy analysis on different dose of GnRHa treating adenomyosis complicated with sterility. Mod. Diagn. Treat. 18: 25-26.

Weeks AD (1999). Uterine ultrasonographic changes with gonadotropin releasing hormone agonists. Am. J. Obstet. Gynecol. 180: 8-10.

Wei S, Gong Z, Wei M, Xie K, et al. (2011). GnRH agonist active immunization influences gonadotropin receptor expression in pituitary gland, uterine development and secretion of peripheral reproduction hormones in female mice. CEMED 5: 243-253.

Wei S, Gong Z, Dong J, Ouyang X, et al. (2012). Effect of a GnRH agonist on the FSH receptors in prepubertal ewes. Small Rumin. Res. 105: 237-243.

Wei S, Chen S, Gong Z, Ouyang X, et al. (2013). Alarelin active immunization influences expression levels of GnRHR, FSHR and LHR proteins in the ovary and enhances follicular development in ewes. Anim. Sci. J. 84: 466-475. 